\title{
Development of a novel BCL6 PROTAC to provide insight into small molecule targeting of BCL6
}

William McCoull, ${ }^{*, \#, \dagger}$ Tony Cheung, ${ }^{\#, \S}$ Erica Anderson, ${ }^{\S}$ Peter Barton, ${ }^{\dagger}$ Jonathan Burgess,${ }^{\dagger}$

Kate Byth,${ }^{\S, \diamond}$ Qing Cao, ${ }^{\S, \Delta}$ M. Paola Castaldi, ${ }^{\S}$ Huawei Chen,${ }^{\S}$ Elisabetta Chiarparin, ${ }^{\dagger}$ Rodrigo

J. Carbajo, ${ }^{\dagger}$ Erin Code,${ }^{\S}$ Suzanna Cowan, ${ }^{\dagger, \Omega}$ Paul R. Davey, ${ }^{\dagger}$ Andrew D. Ferguson, ${ }^{\S}$ Shaun Fillery, ${ }^{\dagger}$ Nathan O. Fuller, ${ }^{\S, \llbracket}$ Ning Gao,${ }^{\S}$ David Hargreaves, ${ }^{\dagger}$ Martin R. Howard,${ }^{\dagger}$ Jun Hu,,${ }^{\S,}$ Aarti Kawatkar, ${ }^{\S}$ Paul D. Kemmitt,${ }^{\dagger}$ Elisabetta Leo,${ }^{\dagger}$ Daniel M. Molina,${ }^{\ddagger}$ Nichole O’Connell, ${ }^{\S,}$ Philip Petteruti, ${ }^{\S}$ Timothy Rasmusson, ${ }^{\S, \Phi}$ Piotr Raubo,${ }^{\dagger}$ Philip B. Rawlins, ${ }^{\dagger}$ Piero Ricchiuto, ${ }^{\dagger}$ Graeme R. Robb,${ }^{\dagger}$ Monica Schenone,${ }^{\bar{\top}}$ Michael J. Waring, ${ }^{\dagger, \perp}$ Michael Zinda, ${ }^{\S,\rfloor}$ Stephen Fawell ${ }^{\S}$ and David M. Wilson. ${ }^{\dagger}$

†Oncology and Discovery Sciences, IMED Biotech Unit, AstraZeneca, 310 Cambridge Science Park, Milton Road, Cambridge, CB4 0WG, UK.

${ }^{\S}$ Oncology and Discovery Sciences, IMED Biotech Unit, AstraZeneca, Gatehouse Park, Waltham, Massachusetts 02451, USA

\$Pelago Bioscience AB, Banvaktsvägen 20, 17148 Solna, Sweden ${ }^{\bar{\top}}$ Broad Institute of Harvard and MIT, 7 Cambridge Center, Massachusetts 02142, USA

ABSTRACT: B-cell lymphoma 6 (BCL6) inhibition is a promising mechanism for treating hematological cancers but high quality chemical probes are necessary to evaluate its therapeutic potential. Here we report potent BCL6 inhibitors that demonstrate cellular target engagement and exhibit exquisite selectivity for BCL6 based on mass spectrometry analyses following chemical proteomic pulldown. Importantly, a proteolysis-targeting chimera (PROTAC) was also developed and shown to significantly degrade BCL6 in a number of 
diffuse large B-cell lymphoma (DLBCL) cell lines, but neither BCL6 inhibition nor degradation selectively induced marked phenotypic response. To investigate, we monitored PROTAC directed BCL6 degradation in DLBCL OCI-Ly1 cells by immunofluorescence and discovered a residual BCL6 population. Analysis of sub-cellular fractions also showed incomplete BCL6 degradation in all fractions despite having measurable PROTAC concentrations, together providing a rationale for the weak antiproliferative response seen with both BCL6 inhibitor and degrader. In summary, we have developed potent and selective BCL6 inhibitors and a BCL6 PROTAC that effectively degraded BCL6, but both modalities failed to induce a significant phenotypic response in DLBCL despite achieving cellular concentrations.

The transcriptional repressor B-cell lymphoma 6 (BCL6) is required for germinal center (GC) formation and maintenance during the humoral immune response but has also been implicated to play a role in lymphomas derived from GC B-cells. Given the role of BCL6 in blocking cell cycle progression and attenuating DNA damage response to promote antibody affinity maturation in antigen activated B-cells, ${ }^{1}$ it is plausible to hypothesize that deregulating BCL6 would lead to maintenance of a highly proliferative GC phenotype with accumulating DNA damage, eventually leading to malignant transformation. Indeed, BCL6 was found to be deregulated in diffuse large B-cell lymphoma (DLBCL) and follicular lymphoma cancers through a number of genetic alterations ${ }^{2,3}$ and its oncogenic potential was validated in transgenic mice constitutively expressing I $\mu$ HA-BCL6 eventually developing lethal DLBCL-like tumours. ${ }^{4}$ Furthermore, BCL6 dependency in the disease setting was demonstrated through BCL6 shRNA-induced lethality in DLBCL cell lines, ${ }^{1}$ while small molecule BCL6 inhibitors based on a promiscuous inhibitor class ${ }^{5}$ and peptido-mimetic ${ }^{6}$ inhibitors have been reported to lead to an anti-proliferative phenotype in DLBCL. 
Consequently, BCL6 has been proposed as an attractive cancer therapeutic target ${ }^{7}$ but as many cancer targets do not fulfill the promise of their preclinical data, ${ }^{8}$ there is a need for potent and selective tools to improve understanding of the BCL6 inhibition phenotype in DLBCL.

The protein-protein interaction (PPI) between a homodimer of the $N$-terminal broadcomplex, tramtrack and bric a brac (BTB) domain of BCL6 and corepressors silencing mediator for retinoid or thyroid-hormone receptors (SMRT), nuclear receptor corepressor (NCOR) and BCL6 corepressor (BCOR),, 10 leads to the repression of genes through which the survival and proliferation effects of GC B-cells is allowed to progress. ${ }^{11}$ Within medicinal chemistry, PPI inhibition provides a significant challenge, ${ }^{12}$ potentially explaining the lack of BCL6 inhibitors published to date. Recently, a high affinity BCL6-binding peptide has been reported, ${ }^{13}$ as well as a fragment-screen derived small molecule binder. ${ }^{14}$ We also recently reported high affinity, selective small molecule cellular probes for BCL6 but they failed to demonstrate a significant BCL6 dependent antiproliferative effect in DLBCL cell lines. ${ }^{15}$ Here, we present a new series of high activity, selective small molecule BCL6 inhibitors which we were also able to convert into chemical biology tools. Cellular target engagement was confirmed through BCL6 thermal stabilization (CETSA) ${ }^{16}$ and further demonstrated through BCL6 specific degradation in a number of cell lines with a PROTAC molecule, but neither the BCL6 inhibitor nor degrader showed improved or selective antiproliferative response compared to our previously reported inhibitors. Through additional investigation, we showed by immunofluorescence imaging and sub-cellular fractionation studies that the degradation of BCL6 with PROTAC appears incomplete, as a residual population remains despite measurable PROTAC concentrations. 


\section{RESULTS AND DISCUSSION}

Developing PROTAC ready BCL6 ligands. To design small molecule ligands suitable for converting to effective PROTACs, we considered high permeability to be a primary requirement in addition to cellular potency and selectivity. Our previous Pyrazolo[1,5a]Pyrimidine (PP) series $^{15}$ of BCL6 binders lacked sufficient permeability and thus a new 5Chloro-Pyrimidine (CP) chemical series was evolved from fragment screening hit $\mathbf{1}$ (Figure 1A). A similar fragment hit has recently been reported. ${ }^{14}$ 2D NMR analysis confirmed that triazine 1 bound BCL6 competitively with its corepressor SMRT and a crystal structure further confirmed the position of the ligand along the lateral groove formed between both chains of the homodimer (Figure 1B). Screening of structural near neighbors of 1 identified the CP 2 with greater than 100-fold activity increase which was also confirmed to bind in the lateral groove in a crystal structure (Figure 1C). The fluorine is directed towards, but does not contact, Glu115 thus a lactam group was added to make a hydrogen bonding interaction with Glu115 and this gave a 12-fold increase in activity in 3. Such 2-NH-pyrimidine motifs are precedented in kinase inhibitors ${ }^{17,18}$ and since this $\mathrm{NH}$ does not form an obvious interaction with BCL6 protein on binding, it was removed through incorporation into a morpholine ring in $\mathbf{4}$ to maintain BCL6 activity but reduce kinase inhibitory activity (Table S1). The bound conformation of $\mathbf{4}$ was not the lowest energy conformation of the isolated ligand and the free-ligand conformational analysis by NMR showed that the bound conformation of 4 is only 50\% populated (Figure S1A). Consequently, macrocyclization to 5 was predicted to favour the bioactive conformation and this achieved a further 5-fold activity increase. Free-ligand analysis of macrocycle $\mathbf{5}$ shows a pattern of NMR signals indicative of a rigid linker and a single $100 \%$ populated conformer in solution. Finally, switching to piperazine $\mathbf{6}$ allowed the opportunity to convert either of the NMe groups to a linker for 
attachment of probe moieties, and the addition of a fluorine in the 6-position of the pyrimidine was tolerated for potency.

A<smiles>Nc1ncnc(Nc2ccccc2Cl)n1</smiles>

1
$>10(829) \mu \mathrm{M}$

2

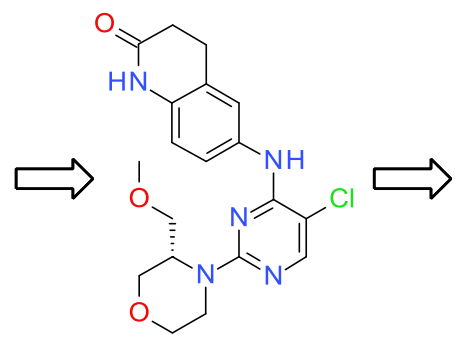

4

$0.14 \mu \mathrm{M}$

$2.9 \mu \mathrm{M}$

3

$0.24 \mu \mathrm{M}$
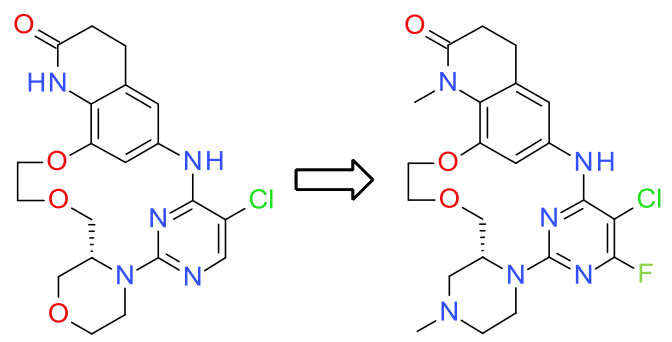

5

$0.026 \mu \mathrm{M}$

$0.0089 \mu \mathrm{M}$

B

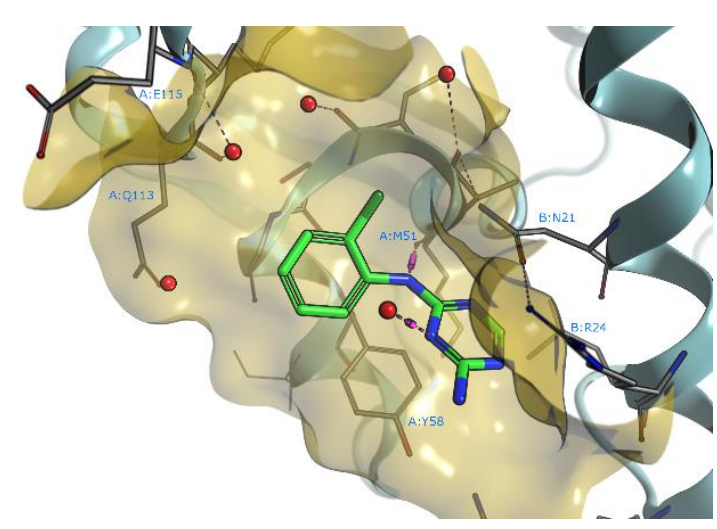

C

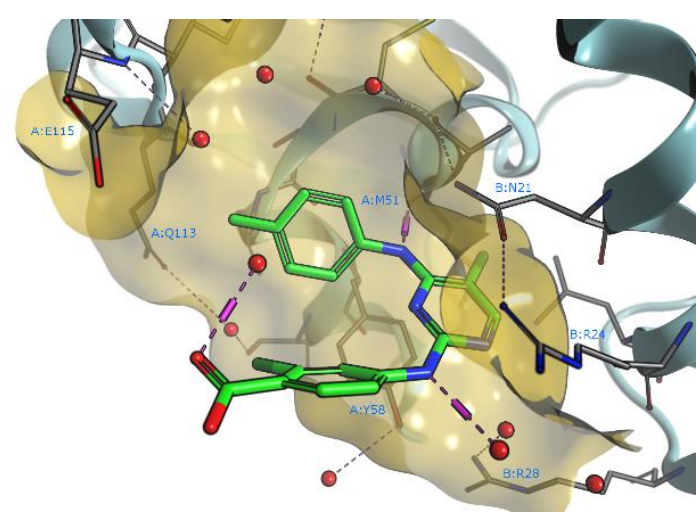

Figure 1. Optimization of fragment hit to high activity binder of BCL6. (A) Fragment screening hit 1 led to identification of structural near neighbour 2. Crystal structure guided optimization afforded 3. Full substitution of pyrimidyl 2-NH of $\mathbf{3}$ removed kinase inhibition in 4. Macrocyclization fixes bioactive conformation of ligand 5 to improve binding activity. Introduction of piperazine allows for two NMe connection points to attach linkers to ligand $\mathbf{6}$. 
$10^{5}$ overall improvement in binding activity achieved during optimization from $\mathbf{1}$ to $\mathbf{6}$ based on FRET IC I0 $_{50}\left(\right.$ SPR K $\mathrm{d}_{\mathrm{d}}$ ) values shown in $\mu \mathrm{M}$ (pIC50 SEM <0.39). (B) Crystal structure of $\mathbf{1}$ (PDB code 6ew6) in complex with BCL6 BTB domain homodimer with NH to Met51 interaction highlighted. (C) Crystal structure of 2 (PDB code 6ew7) in complex with BCL6 BTB domain homodimer showing space to add lactam to interact with Glu115 backbone NH.

To demonstrate cellular target engagement of $\mathbf{6}$, we utilized a cellular thermal shift assay (CETSA) where ligand binding to BCL6 results in increased protein stability and the requirement of higher melt temperatures to induce protein unfolding. ${ }^{16}$ In the DLBCL cell line OCI-Ly1, small but reproducible shifts in the melt curves for BCL6 were observed in the presence of BCL6 binder 7 with no shift observed with the non BCL6 binder 8 as expected (Figure S2A). Within the shift region at $58^{\circ} \mathrm{C}$, an isothermal dose response was calculated to determine an $\mathrm{EC}_{50}$ value for $\mathbf{6}$ and other compounds from $\mathrm{CP}$ and PP series (Figure 2A, S2B and S2C). Potencies correlated closely with $\mathrm{IC}_{50}$ values from a cellular assay measuring de-repression of BCL6 transcriptional silencing of a luciferase reporter in HEK 293T/17 cells, providing confidence CETSA potencies were indicative of BCL6 inhibition (Figure 2B).

A

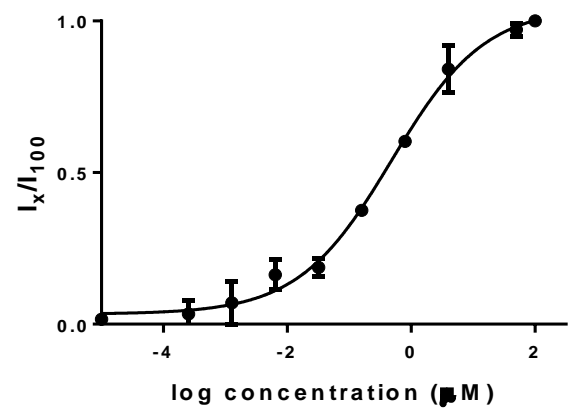




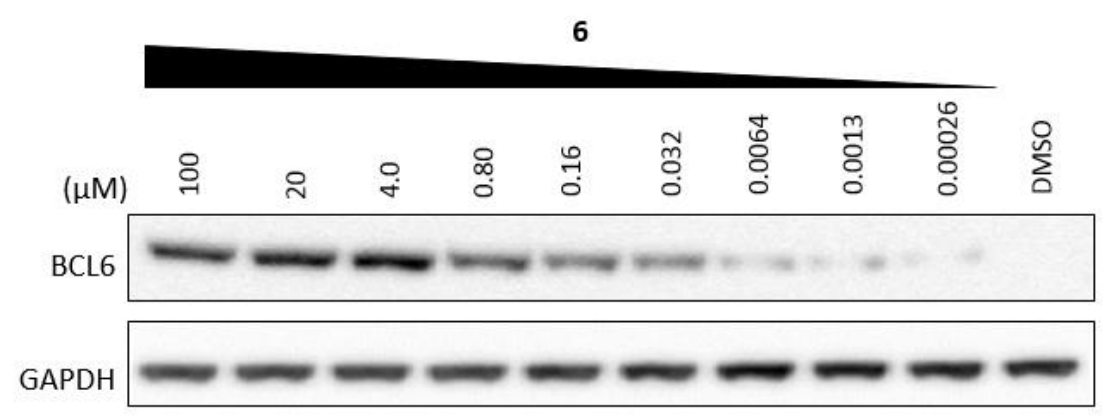

B

\begin{tabular}{|l|l|l|l|}
\hline Cpd & CETSA EC $_{50}(\boldsymbol{\mu M})^{a}$ & $\begin{array}{l}\text { BCL6 cell reporter IC }_{50} \\
(\mu M)^{b}\end{array}$ & Series \\
\hline 5 & 4.9 & 3.4 & CP \\
\hline 6 & 0.48 & 0.71 & CP \\
\hline 7 & 0.34 & 0.33 & PP \\
\hline 8 & no thermal shift & $>32$ & PP \\
\hline
\end{tabular}

${ }^{a} \mathrm{pIC}_{50} \mathrm{SEM}<0.070,{ }^{b} \mathrm{pIC}_{50} \mathrm{SEM}<0.095$

C

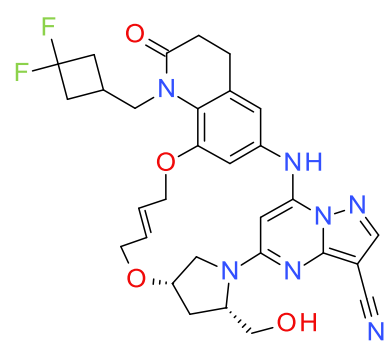

7

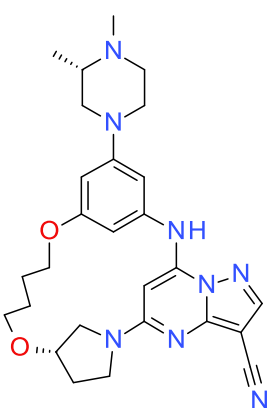

8

Figure 2. Confirmation of cellular BCL6 target engagement using CETSA in OCI-Ly1 cells.

(A) Isothermal dose response of BCL6 stabilization compared to DMSO at $58^{\circ} \mathrm{C}$ in the presence of 6 (upper panel). Dose response curve was generated by normalizing BCL6 protein level to GAPDH and subsequently to BCL6 at $100 \mu \mathrm{M}$ compound (lower panel). (B) Comparison of potency measured by BCL6 cell reporter and CETSA. See also Figure S2. (C) Chemical structures of BCL6 binder 7 and non BCL6 binder 8.

In addition, BCL6 selectivity was observed for $\mathbf{6}$ and the CP series. In a cell reporter assay, similar to the one previously mentioned, but instead measuring de-repression of a 
related BTB domain protein, PLZF, 6 displayed no activity (> $32 \mu \mathrm{M})$. Also, no significant kinase inhibition was observed for 6 against an extensive panel of 399 kinases $(<25 \%$ inhibition at $1 \mu \mathrm{M}$, Table S2). Finally, MS chemical proteomic pulldown utilizing a CP series compound established that BCL6 was the primary target. To develop the affinity probe for proteomic pulldown, the lactam nitrogen was utilized as a site for attachment of affinity beads since substitution at this position is directed away from BCL6 protein based on crystal structure of 9 (Figure 3A). Consequently, 10 can be considered a surrogate for an affinity probe of the CP series (Figure 3B).

Freshly prepared OCI-Ly1 cell lysates were treated at 4, 40 and $400 \mu \mathrm{M}$ with high activity CP ligand $\mathbf{1 2}$ followed by incubation of the beads derivatized with the immobilized CP compound (31). BCL6 was the most enriched protein identified (Figures 3D and S3A). In contrast, utilizing a PP series ligand $13^{15}$ tested at 4, 40 and $200 \mu \mathrm{M}$ (reduced compared to $\mathbf{1 2}$ due to lower solubility of PP series compounds) followed by treatment with the bead immobilized PP affinity probe (45) identified CK2 and CK2 binding partners in addition to BCL6, consistent with its known off-target CK2 activity (Figure 3C and 3D). Taking these results together, selectivity of the $\mathrm{CP}$ series made it more attractive to pursue with further chemical biology probes.

A
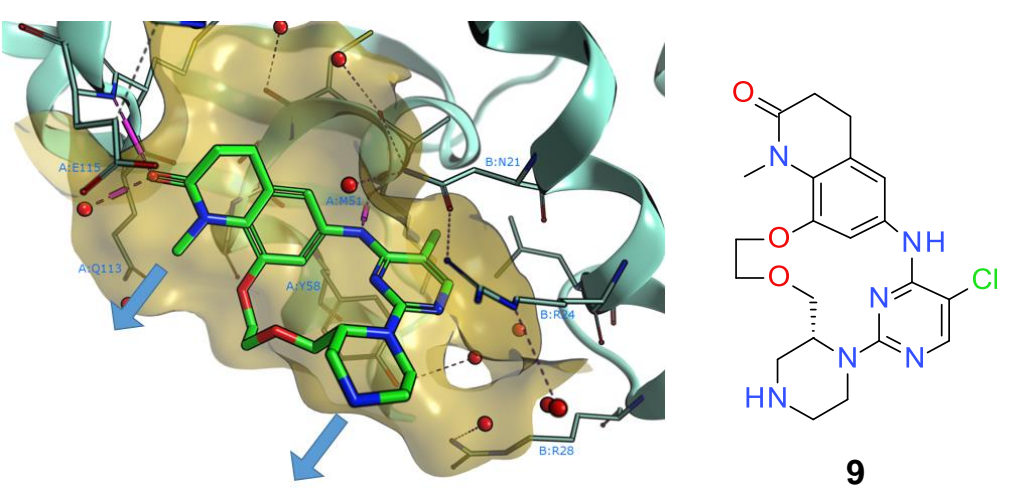

9

B 


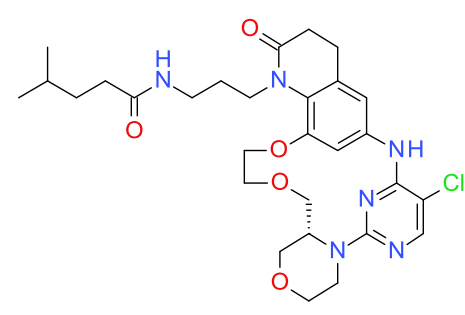

10

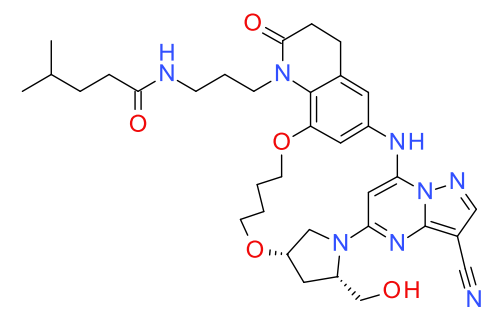

11

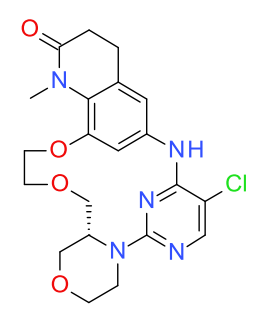

12

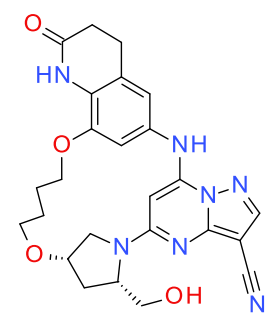

13

C

\begin{tabular}{|l|l|l|l|l|}
\hline Cpd & $\begin{array}{l}\text { BCL6 FRET } \\
\text { IC }_{\mathbf{5 0}}(\boldsymbol{\mu M})^{\boldsymbol{a}}\end{array}$ & $\begin{array}{l}\text { CK2 } \\
\text { IC }_{\mathbf{5 0}}(\boldsymbol{\mu M})^{\boldsymbol{b}}\end{array}$ & $\begin{array}{l}\text { Caco2 Permeability } \\
\mathbf{P}_{\text {app }}\left(\mathrm{x} \mathrm{10^{-6 }} \mathrm{cm}^{-1} \mathrm{~s}^{-1}\right.\end{array}$ & series \\
\hline $\mathbf{1 0}$ & 0.046 & $>10$ & 29 & $\mathrm{CP}$ \\
\hline $\mathbf{1 1}$ & 0.0097 & 0.36 & 2.8 & $\mathrm{PP}$ \\
\hline $\mathbf{1 2}$ & 0.019 & $>10$ & 49 & $\mathrm{CP}$ \\
\hline $\mathbf{1 3}$ & 0.0024 & 0.40 & 12 & $\mathrm{PP}$ \\
\hline
\end{tabular}

${ }^{a} \mathrm{pIC}_{50} \mathrm{SEM}<0.40,{ }^{b} \mathrm{pIC}_{50} \mathrm{SEM}<0.18$

D

$\mathrm{CP}:$

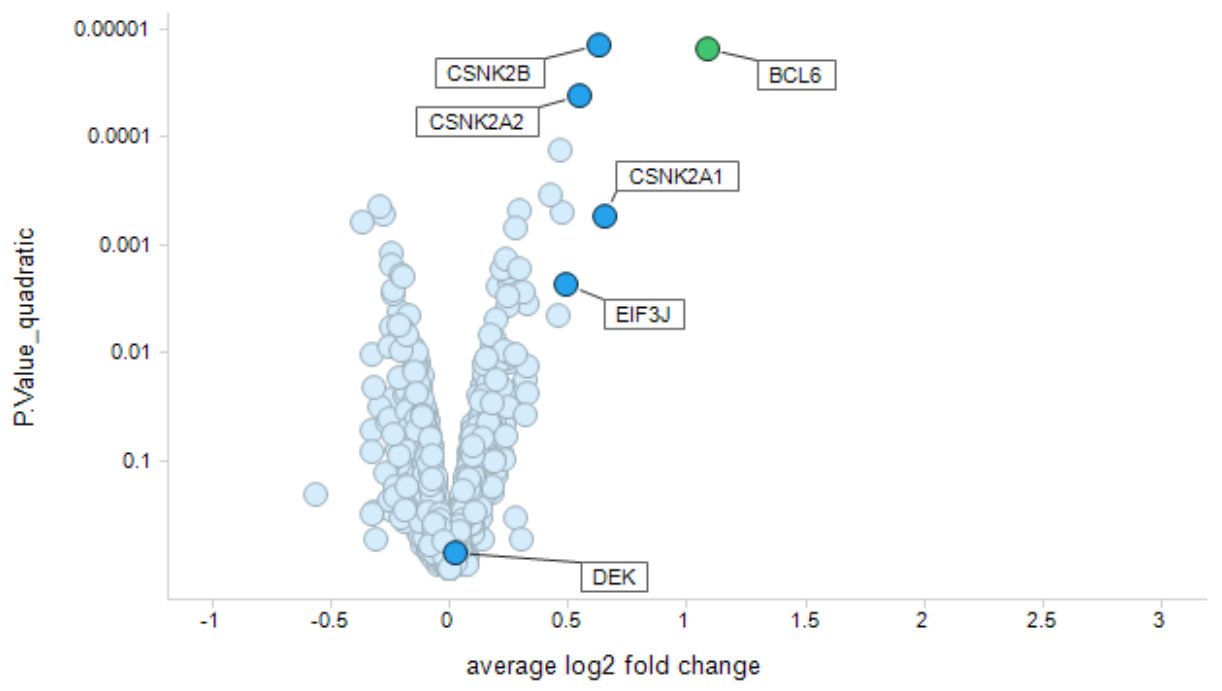

PP: 


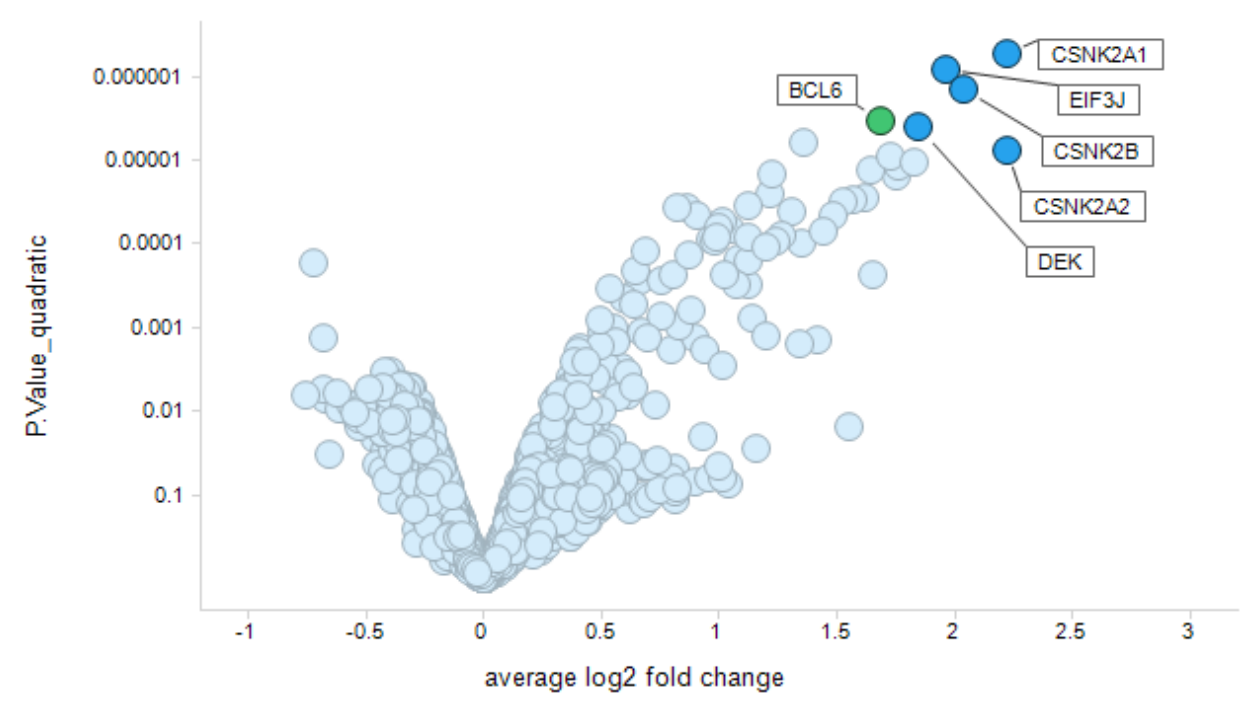

Figure 3. CPs are selective for BCL6. (A) Vectors from both lactam $\mathrm{N}$ and piperazine $\mathrm{N}$, in crystal structure of 9 (PDB code 6ew8) in complex with BCL6 BTB domain homodimer, are directed towards solvent accessible space thus allowing for substitution. (B) Chemical structures of surrogate probe compounds (10 and 11) and chaser compounds (12 and 13) used in MS proteomics. (C) CPs have higher biochemical selectivity against CK2, and higher permeability than corresponding PPs. (D) Impact of CP and PP on the proteome. Chemical proteomics data have been analyzed with DOSCHEDA ${ }^{19}$ and plotted as average fold change versus $\mathrm{P}$ value for proteins quantified. BCL6 (green), CK2 subunits (CSNK2A1, CSNK2A2, CSNK2B), and CK2 binding partners (EIF3J, DEK) are highlighted on each plot.

BCL6 PROTAC degrades BCL6 in a number of hematological cells. BCL6 is known to be targeted for ubiquitination and degradation by the SKP1-CUL1-Fbox protein (SCF) ubiquitin ligase complex that contains F-box protein FBXO11, and it has been demonstrated that lack of FBXO11 correlated with increased DLBCL tumourogenicity in mice. ${ }^{20}$ This tumourogenicity was reduced by reconstitution of FBXO11, indicating that a BCL6 degrader could be a useful mechanism of action, alternative to inhibition, for the treatment of DLBCL cancer as well as providing insight into the differences between these 
two modes of action. More recently, small molecule BCL6 binders were discovered that ubiquitinated and degraded BCL6 through a proteasome dependent pathway and showed improved phenotypic effects in DLBCL cell lines compared to similar molecules that only disrupted BCL6 and corepressor interaction. ${ }^{21}$ Degradation through PROTACs ${ }^{22,23}$ is a new but rapidly growing area of chemical biology and we elected to take this approach with our selective molecules with the aim of further understanding BCL6 dependency in DLBCL. Although the lactam nitrogen was used as the connection point for the linker to the proteomics bead, an alternative piperazine nitrogen was utilized as the connection point for a linker to a PROTAC warhead. Whilst both connection points are directed away from the protein, polar amide containing linker groups were slightly better tolerated for maintaining cellular activity when attached at the piperazine nitrogen (for example cell $\mathrm{IC}_{50} 3.1 \mu \mathrm{M}$ for $\mathbf{1 4}$ compared to cell $\mathrm{IC}_{50} 7.4 \mu \mathrm{M}$ for 10). Surrogate compound 14 maintained BCL6 activity thus demonstrating that amide linkers of the piperazine group could indeed be utilized as BCL6 binders (Figure 4A). Thalidomide is known to recruit the E3 ubiquitin ligase cereblon $(\mathrm{CRBN})$, a component of a cullin-RING ubiquitin ligase (CRL) complex, to target proteins for degradation through the ubiquitin-proteosome pathway ${ }^{24-26}$, and linking thalidomide to a BCL6 ligand provided an opportunity to specifically target BCL6 for CRBN mediated degradation. Attaching a thalidomide warhead via a two-unit PEG, hydroxypropylamine butanediamide linker to 14 led to the formation of PROTAC 15 (Figure 4A). 


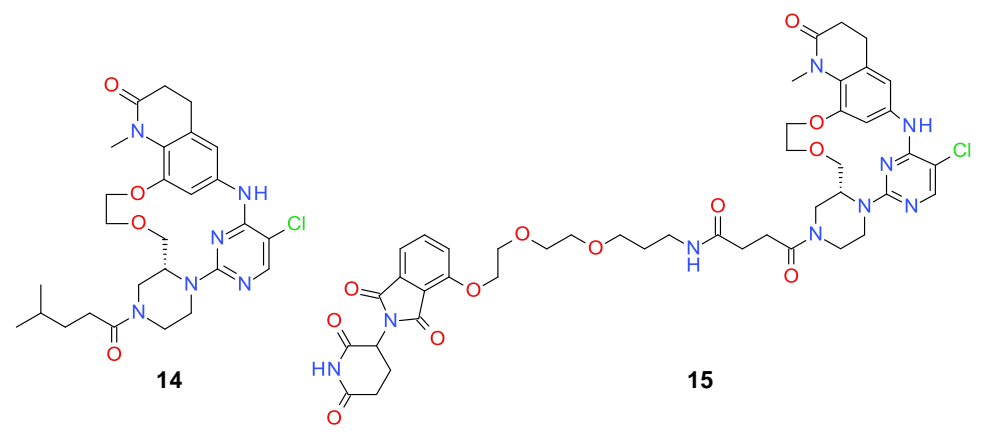

B

\begin{tabular}{|l|l|l|l|l|l|l|l|}
\hline Cpd & $\begin{array}{l}\text { BCL6 } \\
\text { FRET } \\
\mathbf{I C}_{\mathbf{5 0}} \\
(\boldsymbol{\mu M})^{a}\end{array}$ & $\begin{array}{l}\text { BCL6 cell } \\
\text { reporter } \\
\mathbf{I C}_{\mathbf{5 0}}(\boldsymbol{\mu M})^{b}\end{array}$ & $\begin{array}{l}\text { PLZF } \\
\text { cell } \\
\mathbf{I C}_{\mathbf{5 0}} \\
(\boldsymbol{\mu M})^{c}\end{array}$ & $\begin{array}{l}\text { Caco2 } \\
\text { Permeability } \\
\left(\mathrm{x} \mathrm{10^{-6 }} \mathrm{cm} \cdot \mathrm{s}^{-1}\right)\end{array}$ & logD & $\begin{array}{l}\text { Solubility } \\
(\boldsymbol{\mu M})\end{array}$ & $\begin{array}{l}\text { Human plasma } \\
\text { protein binding } \\
(\boldsymbol{\%} \text { free })\end{array}$ \\
\hline $\mathbf{1 4}$ & 0.063 & 3.1 & $>32$ & 31 & 4.2 & 6 & 3.4 \\
\hline $\mathbf{1 5}$ & 0.12 & 8.8 & $>32$ & 0.081 & 1.6 & 22 & 11 \\
\hline
\end{tabular}

${ }^{a} \mathrm{pIC}_{50} \mathrm{SEM}<0.21 ;{ }^{b} \mathrm{pIC}_{50} \mathrm{SEM}<0.039 ;{ }^{c} \mathrm{n}=1$

Figure 4. CP PROTAC has favorable properties for cellular activity. (A) Chemical structures of surrogate probe compounds 14 and PROTAC 15. (B) PROTAC has similar potency and physicochemical properties to surrogate but lower lipophilicity and permeability.

The ${ }^{1} \mathrm{H}-\mathrm{NMR}$ of $\mathbf{1 5}$ showed two species exchanging in solution corresponding to the cis-trans isomers of the amide linker to the piperazine group, in a ratio 55(cis):45(trans). The free-ligand conformational analysis of $\mathbf{1 5}$ showed that the macrocycle moiety presents the same NMR pattern (NOE, $J$ coupling and chemical shift) observed for compound $\mathbf{5}$, with both matching the bioactive conformation of 9 (Figure S1B). The linker portion of PROTAC 15 displayed a high degree of flexibility, not showing any conformational preference and the macrocycle and thalidomide moieties did not show any spatial interaction, acting as independent units in solution. These properties could be beneficial to achieve the bifunctional interaction necessary for a functional PROTAC. The binding of $\mathbf{1 5}$ was approximately 2-fold of $\mathbf{1 4}$ and this relationship was maintained in a BCL6 cell reporter assay with clear selectivity over PLZF (Figure 4B). A reduction in lipophilicity and permeability 
for $\mathbf{1 5}$ was expected due to the polar nature of thalidomide and linker but other physicochemical properties such as solubility and protein binding were improved. Our selection of the $\mathrm{CP}$ series as a very high permeability startpoint was critical to achieving sufficient, albeit low, permeability to enable cellular activity.

Degradation of BCL6 with PROTAC 15 was extensively evaluated in the DLBCL cell line OCI-Ly1. BCL6 degradation was dose dependent but not complete, with $82 \%$ degradation, relative to DMSO, being achieved at $1 \mu \mathrm{M}$ of $\mathbf{1 5}$ (Table S5), and appears specific to BCL6 as TBLR1, ${ }^{27}$ a transcriptional cofactor in the BCL6-corepressor complex, was unaffected (Figures 5A and S4A). Kinetically, significant degradation of BCL6 was evident as early as $1 \mathrm{~h}$ and maintained out to at least $72 \mathrm{~h}$, despite an apparent increase in baseline BCL6 levels over the same time period (Figures 5B and S4B). In contrast, surrogate 14 was comparable to control over the same time period indicating that the thalidomide warhead is responsible for the degradation. Furthermore, addition of the proteasome inhibitor MG132 (Figures 5C and S4C), or chasing with excess BCL6 inhibitor $\mathbf{1 4}$ or a potent thalidomide derivative pomalidomide (Figures 5D and S4D), was able to attenuate the degradation observed with 15. More complete protection was achieved when 14 and pomalidomide were added together. These observations support the PROTAC-based mechanism for BCL6 degradation. Similarly, effective degradation of BCL6 ranging from 59-84\% with $1 \mu \mathrm{M}$ of 15 were achieved in a range of DLBCL and Burkitt's lymphoma (BL) cell lines (Figure 5E and S4E and Table S5).

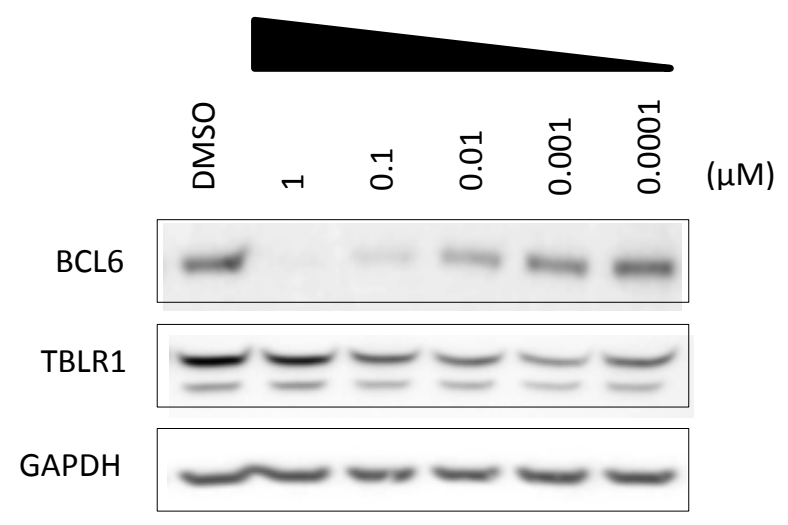


B

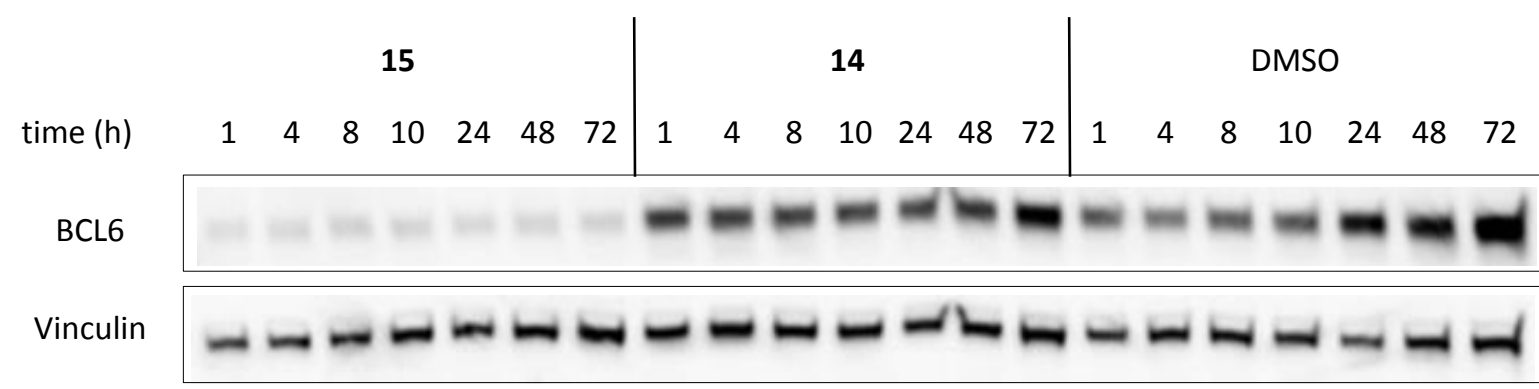

C
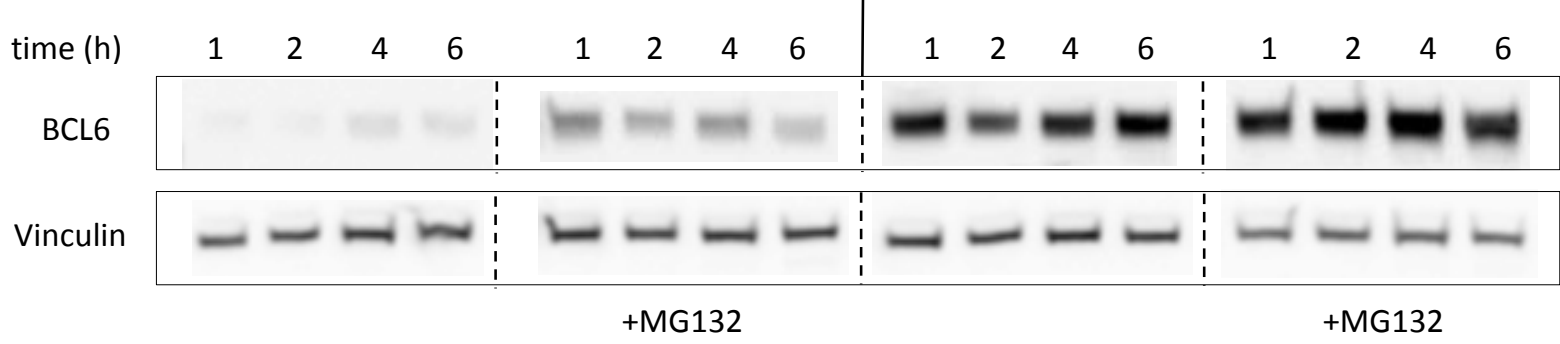

D

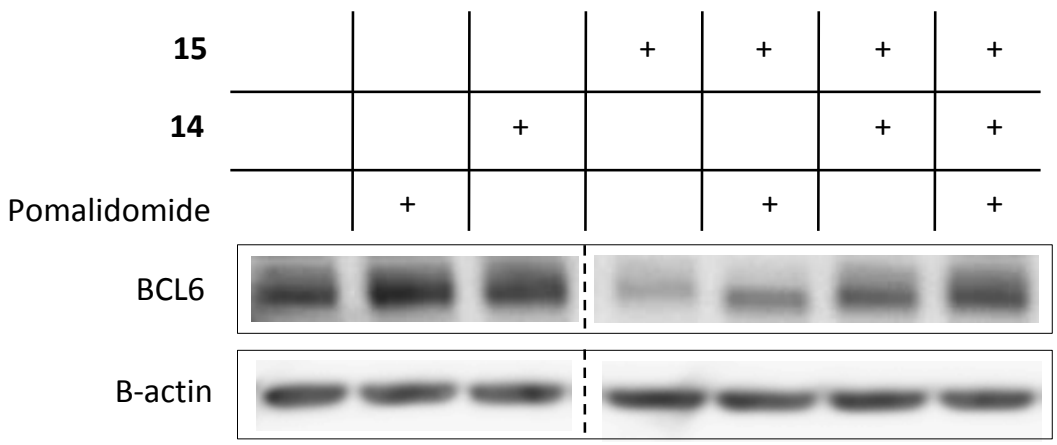

$\mathbf{E}$
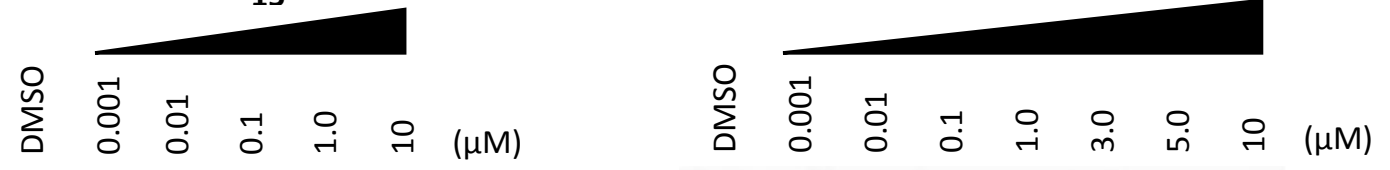
Figure 5. PROTAC 15 degrades BCL6 in hematological cells through a proteasome dependent mechanism. (A) Western blot analysis after treatment of OCI-Ly1 cells with $\mathbf{1 5}$ over $4 \mathrm{~h}$ shows dose dependent degradation of BCL6. (B) Treatment with $1 \mu \mathrm{M}$ concentration of either $\mathbf{1 5}$ or $\mathbf{1 4}$ over $72 \mathrm{~h}$ period shows that only PROTAC degrades BCL6. (C) Addition of proteasome inhibitor MG132 $(5 \mu \mathrm{M})$ partially ablates degradation of BCL6 by $15(1 \mu \mathrm{M})$. (D) Degradation by $15(1 \mu \mathrm{M})$ is attenuated by excess BCL6 inhibitor (1 $\mu \mathrm{M} \mathbf{1 4})$, pomalidomide $(10 \mu \mathrm{M})$, or both at $3 \mathrm{~h}$. (E) 15 degrades BCL6 levels across a range of DLBCL and BL cell lines at $4 \mathrm{~h}$.

\section{BCL6 PROTAC does not improve antiproliferative activity over BCL6}

inhibitors in DLBCL cells. Having demonstrated the BCL6 degradation properties of 15, we investigated what impact this would have on the antiproliferative effects of DLBCL cell lines. Previously we demonstrated that BCL6 inhibition with a PP chemotype led to weak antiproliferative effects across a panel of DLBCL cell lines without apparent selectivity ${ }^{15}$ but now 15 gave the opportunity to evaluate the effect of removal rather than simply inhibition of BCL6. Inhibitors targeting the BCL6 BTB domain will disrupt primary co-repressor (SMRT, NCOR and BCOR) binding but degradation could potentially drive a deeper phenotypic 
response through removing interactions beyond the BCL6-BTB domain. For example, the BCL6 RD2 (repression domain 2) domain has been shown to bind to the MTA3 corepressor to suppress PRDM1 and block plasma cell differentiation, and the combination of BTB domain blockade and MTA3 depletion through siRNA resulted in greater cell killing in the SUDHL4 DLBCL line. ${ }^{28}$ Surprisingly, the PROTAC antiproliferative effect was similar to inhibitor 14, with weak pan-inhibition across the cell line panel (Figure 6A). Included were DLBCL cell lines of both GCB and ABC subtypes with varying levels of BCL6, and a multiple myeloma (MM) cell line, AMO-1, that expresses weak or undetectable levels of BCL6 (Figure 6A, 6B, and S5). ${ }^{29}$ We also evaluated gene expression to identify cell lines ${ }^{30}$ that have high expression of BCL6 and low expression of PRDM1, a reported BCL6 target gene $^{31}$, as an indication of BCL6 functional activity and sensitivity to BCL6 inhibition e.g. OCI-Ly1 and SUDHL4, and the reciprocal profile to predict insensitivity to BCL6 inhibition e.g. OCI-Ly19 and AMO-1 (Figure 6A). This was consistent with previous classifications of OCI-Ly1 and SUDHL4 cells as BCL6 dependent, and OCI-Ly19 cells as BCL6 independent, based on a BCL6 gene signature ${ }^{32}$ and/or sensitivity to BCL6 inhibition or knockdown. ${ }^{1,5,6}$. Antiproliferation studies were conducted over $3 \mathrm{~d}$ but given the possibility a longer time would be required to see maximal effect, as exemplified with EZH2 inhibitors where selective antiproliferative effects in EZH2 mutant lines were not fully realized until after 4 $\mathrm{d},{ }^{33}$ and more recently with a BCL6 degrader where antiproliferative responses showed a slow onset, ${ }^{21}$ a longer $16 \mathrm{~d}$ proliferation study was also conducted.

While PP inhibitor 17 displayed high BCL6 cell reporter potency $\left(\mathrm{IC}_{50}=0.13 \mu \mathrm{M}\right)$, it showed only weak antiproliferative activity in the $3 \mathrm{~d}$ assays against a broad panel of DLBCL cell lines (Figure 6A). A more pronounced phenotype was seen at the end of a $16 \mathrm{~d}$ study tested against a subset of these lines, but given the similar antiproliferative effect between OCI-Ly1, SUDHL4, and OCI-Ly19 (40, 50, and 51\% inhibition at $1 \mu \mathrm{M}$, respectively) 
(Figures 6C, and S6), a BCL6 selective effect did not occur, consistent with the pan-effect seen in the $3 \mathrm{~d}$ assays. Furthermore, PROTAC 15 also did not elicit a selective phenotypic response in the $16 \mathrm{~d}$ study despite demonstrating effective degradation of BCL6 in the same OCI-Ly1 and SUDHL4 cells.

A

\begin{tabular}{|c|c|c|c|c|c|c|c|c|c|c|c|}
\hline & \multicolumn{4}{|c|}{ DLBCL (GCB subtype) } & \multicolumn{3}{c|}{ DLBCL (ABC subtype) } & MM \\
\cline { 2 - 22 } & $\begin{array}{c}\text { OCI- } \\
\text { Ly1 }\end{array}$ & $\begin{array}{c}\text { Karpas } \\
\mathbf{4 2 2}\end{array}$ & $\begin{array}{c}\text { SUDHL } \\
\mathbf{4}\end{array}$ & WILL-2 & $\begin{array}{c}\text { OCI- } \\
\text { Ly19 }\end{array}$ & $\begin{array}{c}\text { OCI- } \\
\text { Ly10 }\end{array}$ & RI-1 & $\begin{array}{c}\text { SUDHL } \\
\mathbf{2}\end{array}$ & $\begin{array}{c}\text { OCI- } \\
\text { Ly3 }\end{array}$ & TMD8 & AMO-1 \\
\hline $\begin{array}{c}\text { Relative protein } \\
\text { expression (BCL6) }\end{array}$ & 274 & 191 & 214 & 41 & 23 & 82 & 51 & 34 & 113 & 22 & 11 \\
\hline $\begin{array}{c}\text { Relative gene } \\
\text { expression (BCL6) }\end{array}$ & 6.2 & 5.6 & 5.2 & 2.3 & 2.2 & 5.3 & 4.7 & 4.7 & 3.6 & 2.9 & 1.5 \\
\hline $\begin{array}{c}\text { Relative gene } \\
\text { expression (PRDM1) }\end{array}$ & 1 & 1.4 & 0.85 & 0.98 & 3.5 & 1 & 1.7 & 4.3 & 4.6 & 5.5 & 4.8 \\
\hline
\end{tabular}

\begin{tabular}{|c|c|c|c|c|c|c|c|c|c|c|c|c|}
\hline $\mathbf{C p d}$ & $\begin{array}{c}\text { BCL6 cell } \\
\text { reporter } \mathrm{pIC}_{50}\end{array}$ & $\mathrm{pGI}_{50}$ & $\mathrm{pGI}_{50}$ & $\mathrm{pGI}_{50}$ & $\mathrm{pGI}_{50}$ & $\mathrm{pGI}_{50}$ & $\mathrm{pGI}_{50}$ & $\mathrm{pGI}_{50}$ & $\mathrm{pGI}_{50}$ & $\mathrm{pGI}_{50}$ & $\mathrm{pGI}_{50}$ & $\mathrm{pGI}_{50}$ \\
\hline $\mathbf{1 4}$ & 5.5 & 5.3 & 5.4 & 5.3 & 5.4 & 5.1 & 5.3 & 5.4 & 5.3 & 5.2 & 5.4 & 5.1 \\
\hline $\mathbf{1 5}$ & 5.1 & 5 & 5.8 & 4.9 & 5.1 & 5 & 4.9 & 5.1 & 5.3 & 5.1 & 5.1 & 4.8 \\
\hline $\mathbf{1 7}$ & 6.9 & 5 & 4.6 & 5 & 5.1 & 4.8 & 5.2 & 5.4 & 5.2 & 4.7 & 4.8 & 4.6 \\
\hline
\end{tabular}

$\mathrm{pIC}_{50} \mathrm{SEM}<0.10$

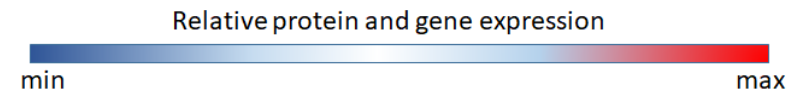

B
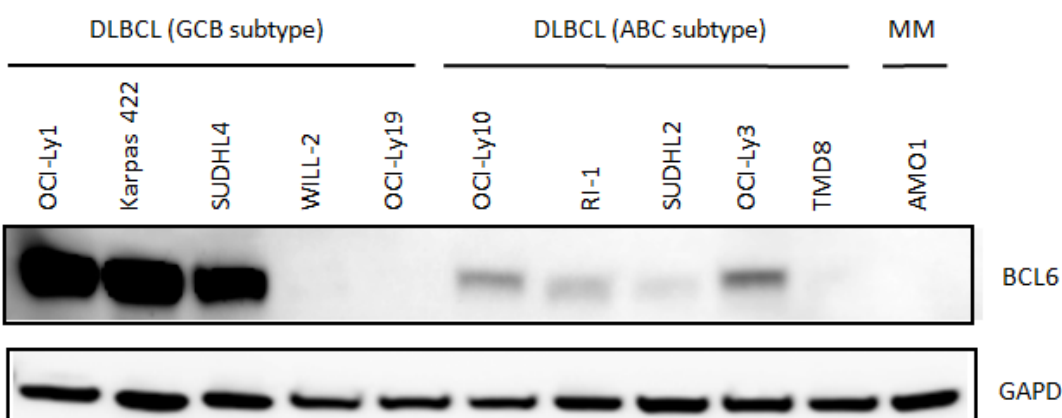

C 


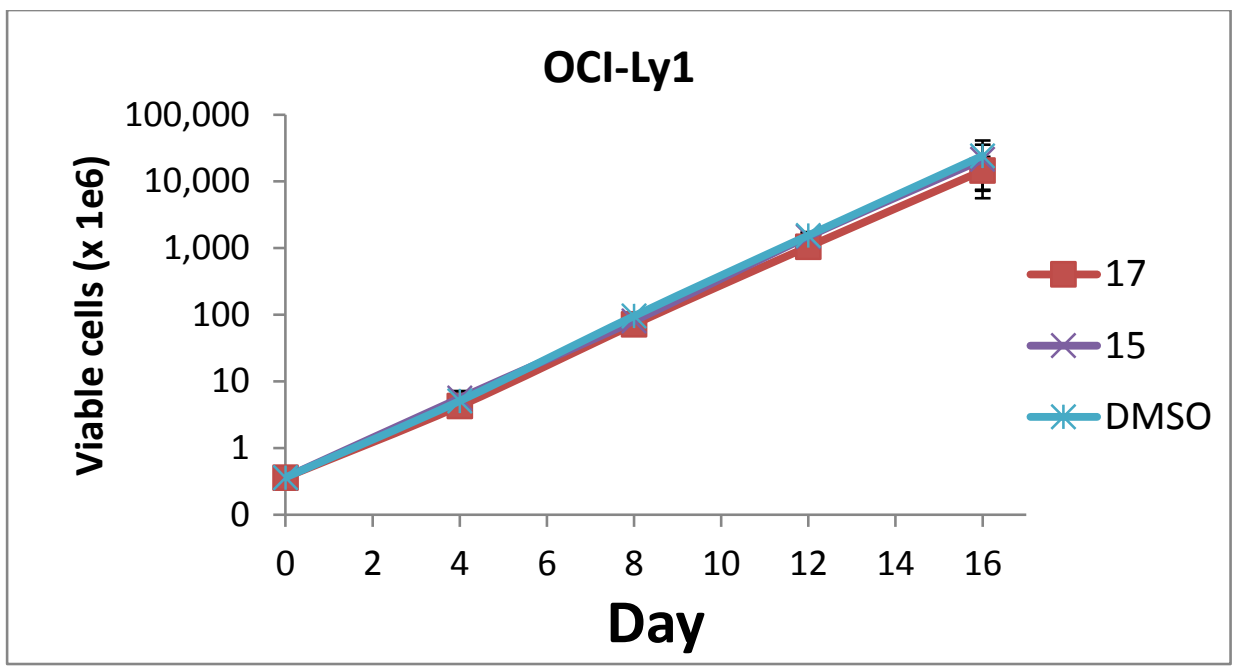

D

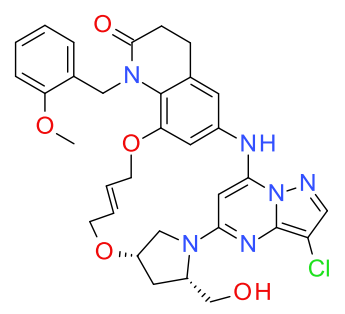

17

Figure 6. BCL6 degradation does not improve antiproliferative activity. (A) BCL6 cell reporter potency and $3 \mathrm{~d}$ cell proliferation data for surrogate 14, PROTAC 15, and inhibitor 17 across a range of DLBCL and a MM line, with BCL6 protein levels assessed by densitometry analysis of Figure 6B shown as average relative density/area. Log2 expression of BCL6 and target gene PRDM1 are also indicated. Details can be found at https://www.ebi.ac.uk/arrayexpress/experiments/E-GEOD-57083/. B) Western blot of BCL6 in tested cells. (C) $16 \mathrm{~d}$ proliferation study of PROTAC $15(1 \mu \mathrm{M})$ in OCI-Ly1 indicating nominal effect compared to DMSO and BCL6 inhibitor $17(1 \mu \mathrm{M})$ despite BCL6 degradation. (D) Chemical structure BCL6 inhibitor 17.

A BCL6 population remains after BCL6 PROTAC treatment. Previously, BCL6 was reported to show both a diffuse and punctate nuclear immunofluorescence (IF) staining pattern depending on phase of cell cycle, with puncta representing BCL6 localization to 
replication foci. ${ }^{34}$ We confirmed this staining pattern in the breast cancer cell line MDAMB-468 which has endogenous expression of BCL6, and demonstrated a decrease in diffuse and punctate nuclear staining of BCL6 from siRNA knockdown (Figure S7). IF imaging of PROTAC 15 treated OCI-Ly1 cells also showed a reduction in diffuse and punctate staining of BCL6, whilst a BCL6 inhibitor $\mathbf{1 8}^{15}$ showed no significant change compared to DMSO, as expected (Figure 7A). However, closer investigation indicated significant punctate staining of BCL6 still remained in the presence of $\mathbf{1 5}$, similar to the staining pattern seen with BCL6 siRNA in MDA-MB-468 cells.

Labelled free compound concentration in cells can be measured by quantitative MS spectrometry, ${ }^{35-38}$ and we extended this approach to sub-cellular fractions to assess specific intracellular compound concentrations to ensure sufficient levels were achieved given incomplete BCL6 degradation by PROTAC. It was expected that intracellular levels of PROTAC 15 would be lower than that of a potent cellular inhibitor 19 (cell $\mathrm{IC}_{50} 0.48 \mu \mathrm{M}$, Caco2 $\mathrm{P}_{\text {app }} 47 \times 10^{-6} \mathrm{~cm} \cdot \mathrm{s}^{-1}$ ) due to differences in permeability and indeed, 15 was measured to have 15-fold lower levels than $\mathbf{1 9}$ (Figure 7B). In terms of absolute levels, 19 was in significant excess of BCL6 cell reporter $\mathrm{IC}_{50}$ within both the cytoplasm and the nucleus and thus it was expected that all available BCL6 would be inhibited. In contrast, levels of $\mathbf{1 5}$ within both the cytoplasm and the nucleus were below the BCL6 cell reporter IC $_{50}$ but the catalytic nature of PROTACs suggests that efficient degradation would still occur. 
DMSO

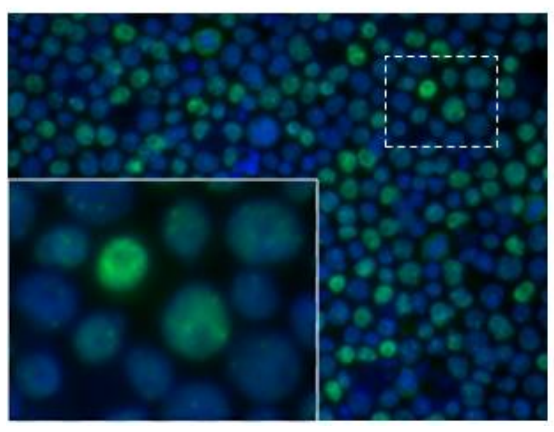

18

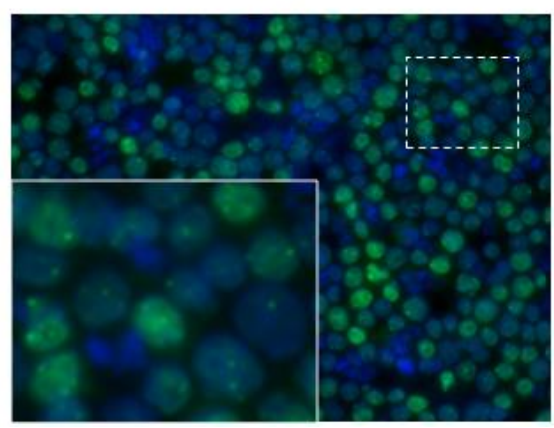

15

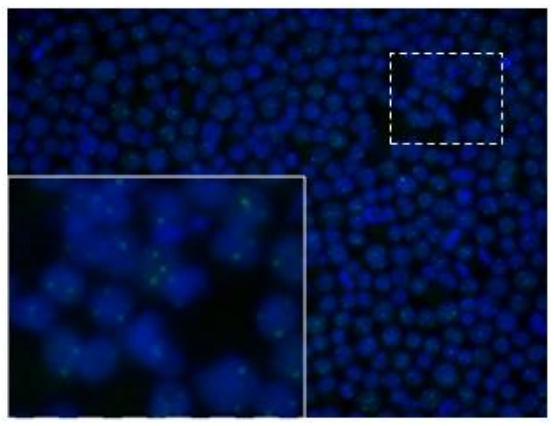

B

\begin{tabular}{|c|c|c|c|c|c|c|c|c|c|}
\hline \multirow[b]{2}{*}{ Cpd } & \multirow{2}{*}{$\begin{array}{l}\text { BCL6 } \\
\text { cell } \\
\text { report } \\
\text { er IC }_{50} \\
(\mu M)^{a}\end{array}$} & \multirow{2}{*}{$\begin{array}{l}\text { Caco2 } \\
P_{\text {app }} \\
\left(1^{-6}\right. \\
\left.\mathrm{cm}^{-6} \cdot \mathrm{s}^{-1}\right)\end{array}$} & \multicolumn{2}{|c|}{$\begin{array}{l}\text { Total cell } \\
\text { concentration }\end{array}$} & \multicolumn{2}{|c|}{$\begin{array}{l}\text { Cytoplasmic } \\
\text { concentration }\end{array}$} & \multicolumn{2}{|c|}{$\begin{array}{l}\text { Nuclear } \\
\text { concentration }\end{array}$} & \multirow{2}{*}{$\begin{array}{l}\text { Nuclear: } \\
\text { cytoplasmic } \\
\text { ratio }\end{array}$} \\
\hline & & & $\begin{array}{l}\text { pmol/ } \\
10^{6} \text { cell }\end{array}$ & $\boldsymbol{\mu} \mathbf{M}$ & $\begin{array}{l}\text { pmol/ } \\
10^{6} \text { cell }\end{array}$ & $\mu \mathbf{M}$ & $\begin{array}{l}\mathrm{pmol} / 10 \\
{ }^{6} \text { cell }\end{array}$ & $\mu \mathbf{M}$ & \\
\hline 15 & 8.8 & 0.081 & 0.77 & 1.0 & 0.45 & 0.76 & 0.0070 & 0.050 & 0.066 \\
\hline 19 & 0.093 & 23 & 11 & 15 & 15 & 26 & 2.1 & 14 & 0.54 \\
\hline
\end{tabular}

${ }^{a} \mathrm{pIC}_{50}$ SEM $<0.065$

C 

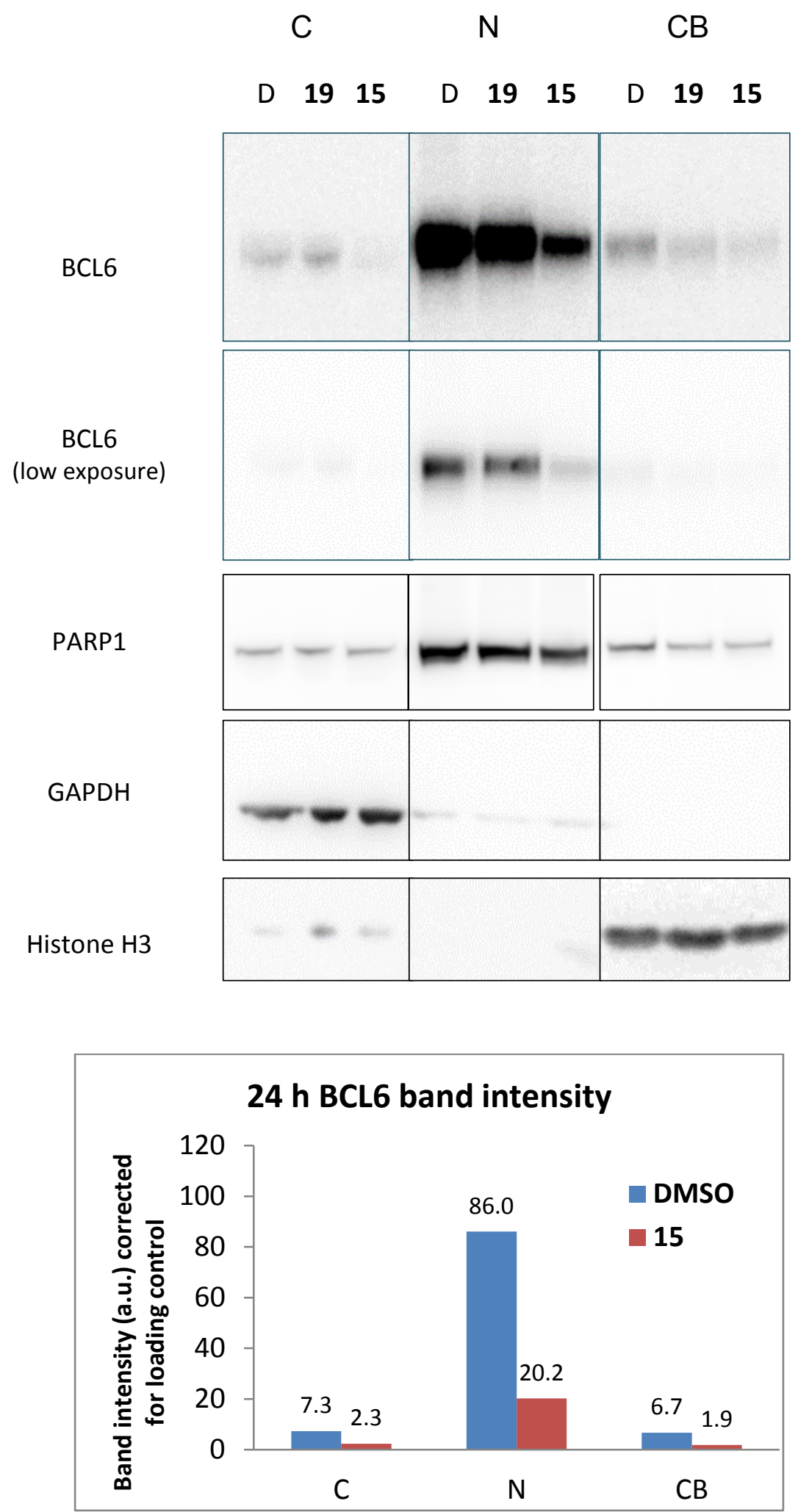

D

\begin{tabular}{|l|l|l|l|l|l|}
\hline Cpd & $\begin{array}{l}\text { BCL6 } \\
\text { cell } \\
\text { reporte }\end{array}$ & $\begin{array}{l}\text { Total cell } \\
\text { concentration }\end{array}$ & $\begin{array}{l}\text { Cytoplasmic } \\
\text { concentration }\end{array}$ & $\begin{array}{l}\text { Soluble } \\
\text { nuclear } \\
\text { concentration }\end{array}$ & $\begin{array}{l}\text { Chromatin } \\
\text { bound } \\
\text { concentration }\end{array}$ \\
\hline
\end{tabular}




\begin{tabular}{|l|l|l|l|l|l|l|l|l|l|}
\hline & $\begin{array}{l}\mathbf{r} \mathbf{I C} \mathbf{5 0}_{\mathbf{5}} \\
(\boldsymbol{\mu M})^{\boldsymbol{a}}\end{array}$ & $\begin{array}{l}\mathbf{p m o l} / \\
\mathbf{1 0}^{\mathbf{6}} \text { cell }\end{array}$ & $\boldsymbol{\mu M}$ & $\begin{array}{l}\mathbf{p m o l} / \\
\mathbf{1 0}^{\mathbf{6}} \text { cell }\end{array}$ & $\boldsymbol{\mu M}$ & $\begin{array}{l}\mathbf{p m o l} / \\
\mathbf{1 0}^{\mathbf{6}} \text { cell }\end{array}$ & $\boldsymbol{\mu M}$ & $\begin{array}{l}\mathbf{p m o l} / \\
\mathbf{1 0}^{\mathbf{6}} \text { cell }\end{array}$ & $\boldsymbol{\mu M}$ \\
\hline $\mathbf{1 5}$ & 8.8 & 0.51 & 0.70 & 0.24 & 0.41 & 0.061 & 0.46 & 0.029 & 1.9 \\
\hline $\mathbf{1 9}$ & 0.093 & 36 & 49 & 4.5 & 7.7 & 6.6 & 50 & 2.5 & 171 \\
\hline
\end{tabular}

${ }^{a} \mathrm{pIC} \mathrm{C}_{50} \mathrm{SEM}<0.065$

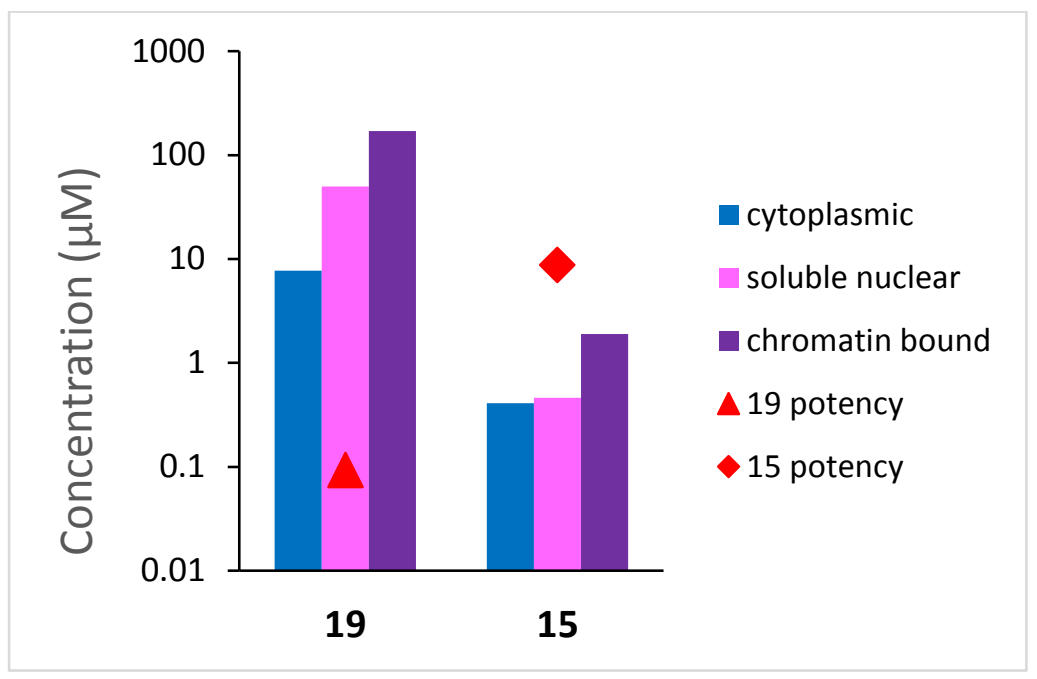

$\mathbf{E}$

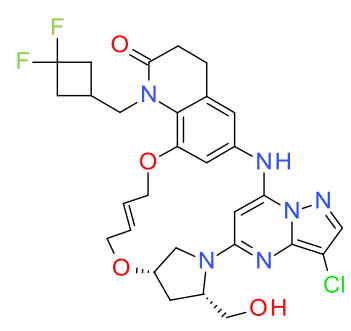

18

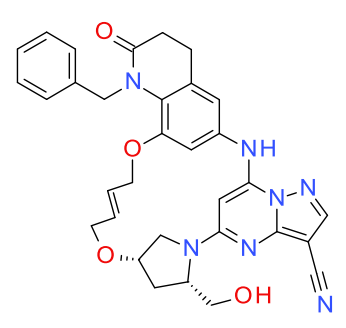

19

Figure 7. Sub-cellular BCL6 levels after PROTAC treatment. (A) Staining for BCL6 (green) and DNA (blue) after treatment of OCI-Ly1 cells with $\mathbf{1 8}^{15}$ and 15 at $10 \mu \mathrm{M}$ for $24 \mathrm{~h}$.

Magnified images show remaining punctate staining with 15. (B) Measurable levels of BCL6 inhibitor 19 and PROTAC 15 within cytoplasm and nucleus after $4 \mathrm{~h}$ treatment of cells at 1 $\mu \mathrm{M}$. (C) Western blot showing BCL6 protein levels in cytoplasmic $(\mathrm{C})$, soluble nuclear $(\mathrm{N})$ and chromatin bound (CB) fractions after $24 \mathrm{~h}$ treatment with 15 and 19 at $1 \mu \mathrm{M}$, or DMSO (D) (upper panel). An equivalent percentage of each fraction was loaded to assess relative levels of BCL6 between subcellular compartments. Quantification of BCL6 levels from western blot shows similar level of degradation by $\mathbf{1 5}$ across all fractions compared to DMSO (lower panel). (D) Measurable levels of BCL6 inhibitor 19 and PROTAC 15 within 
cytoplasm, nucleus and chromatin bound fractions after $4 \mathrm{~h}$ treatment of cells at $1 \mu \mathrm{M}$. (E) Chemical structures BCL6 inhibitors 18 and 19.

Existence of a residual punctate, nuclear BCL6 population after PROTAC treatment could potentially be chromatin bound BCL6 where the transcriptional complex involving BCL6 precluded binding of PROTAC, and by inference, inhibitors which utilize the same binding site. It was possible to obtain separation of sub-nuclear fractions ${ }^{39}$ and assess BCL6 levels together with concentrations for both $\mathbf{1 5}$ and $\mathbf{1 9}$ (Figure 7C and S8). In addition, GAPDH, PARP1, and Histone H3 were monitored to gauge the quality of subcellular separation, and enrichment of these proteins were seen in the cytoplasmic, soluble nuclear, and chromatin bound fractions respectively, in agreement with their known cellular localization. BCL6 was enriched in the soluble nuclear fraction but could still be detected in the cytoplasmic and chromatin bound fractions. While our hypothesis would predict chromatin bound BCL6 to be less accessible to small molecule targeting, this was not supported by our data as significant BCL6 degradation was observed in all fractions with PROTAC 15, but residual levels of BCL6 were still seen. This was more notable in the soluble nuclear fraction, in accord with higher basal levels in this fraction and consistent with the IF staining pattern, but the relative amount of degradation across all fractions was similar. The intracellular levels measured for $\mathbf{1 5}$ and $\mathbf{1 9}$ confirm that both sufficiently access the chromatin bound fraction as well as the soluble nuclear fraction to give rise to degradation or inhibition respectively across all fractions (Figure 7D and S9). The lack of complete degradation is not specific to $\mathbf{1 5}$ and similar PROTACs with different linkers also gave an incomplete BCL6 degradation by western blot analysis (Figure S11).

In this study, we developed chemical biology probes to discover a residual population of BCL6 remained despite PROTAC treatment, potentially providing a rationale for the lack 
of antiproliferative effect seen with small molecule inhibition or degradation of BCL6. A high quality BCL6 inhibitor was required before conversion to a PROTAC. Existing PPs did not have sufficient intrinsic permeability, a key requirement since the addition of the thalidomide PROTAC warhead brings a significant reduction in permeability. Fortunately, a higher permeability CP series was identified from fragment screening followed by structure guided medicinal chemistry optimization. High selectivity for BCL6 was demonstrated with the CP series proving superior over the PP series both in biochemical assays and in a MS proteomics pulldown experiment. The CETSA technique provided evidence of cellular target engagement, confirming our probes effectively bound to BCL6 within the cell, and X-ray crystallography informed the attachment point of a linker to the thalidomide unit where it would not interfere with binding to BCL6. Through this work, we developed a PROTAC with physicochemical properties sufficient to enable cellular activity.

The contrasting effects of a BCL6 inhibitor and a BCL6 PROTAC inform what may be occurring within cells. The BCL6 inhibitor exhibits sub micromolar cellular activity in de-repressing BCL6 while the BCL6 PROTAC 15 degrades BCL6 across a number of DLBCL cell lines via the expected ubiquitin-proteasome mediated pathway. However, both inhibitor and PROTAC 15 exhibit only weak antiproliferative activity seemingly independent of BCL6 expression. Immunofluorescence staining coupled with subcellular concentration analysis provides a rationale for the lack of cellular phenotype seen with both targeting modalities. The inhibitor achieves significant levels within the cell and nucleus without affecting the distribution and protein level of BCL6. PROTAC 15 also achieves significant concentration levels within the cell and nucleus, albeit lower than the inhibitor, to degrade cytoplasmic and nuclear BCL6, but significant nuclear punctate staining still remained. This led us to hypothesize that a chromatin bound BCL6 complex could be more resistant to small molecule targeting, but detailed sub-nuclear fractionation experiments indicated degradation 
occurred in the chromatin bound as well as in the soluble nuclear fractions. Nevertheless, a small, residual BCL6 population still remained across all isolated fractions. Studies to specifically identify and target this residual BCL6 population could provide further insight on BCL6 function in DLBCL and guide future design of successful BCL6 inhibitors. Additionally, combination treatment with a BCL6 inhibitor or degrader may be what is required to elicit a marked phenotypic response in the disease setting, as combinations with inhibitors of EZH2, BCL2 or other oncogenic factors have been previously suggested.7, 40

In summary, BCL6 inhibitors were developed with high activity, good cellular potency, proven in-cell target engagement, excellent selectivity, and significant exposure in the nuclear subcellular fractions, yet did not induce significant antiproliferative activity in a DLBCL cell line panel. A BCL6 PROTAC was designed with similar attributes and shown to effectively degrade BCL6 in all subcellular fractions with the exception of a residual BCL6 population but also failed to induce significant phenotypic response. Together, this data underscores the challenges associated with small molecule targeting of BCL6 as a therapeutic approach.

\section{METHODS}

Please see the Supplementary Information for experimental details

\section{ASSOCIATED CONTENT}

\section{Supporting Information}

The Supporting Information is available free of charge on the ACS Publications website at DOI: $\operatorname{xxxxxxxxxx}$

Supporting Tables S1-5 and Supporting Figures S1-S10 and detailed descriptions of the experimental material and methods applied in this study 


\section{Accession Codes}

The structures of BCL6 BTB domain bound to compounds $\mathbf{1 , 2}$ and 9 have been deposited in the Protein Data Bank with PDB accession codes 6ew6, 6ew7 and 6ew8, respectively.

\section{AUTHOR INFORMATION}

\section{Corresponding Author}

Email: william.mccoull@astrazeneca.com

\section{ORCID}

William McCoull: 0000-0002-2977-1744

Andrew D. Ferguson: 0000-0002-1018-9631

\section{Author Contributions}

${ }^{\#}$ These authors contributed equally.

W.M. designed compounds, coordinated chemistry, analysed and interpreted data and coordinated manuscript preparation. E.A. carried out cell biology experiments and manuscript editing. P.B., J.B, S.F., P.D.K. and T.R. synthesized compounds. P.Ra. designed and synthesized compounds. K.B., H.C., M.Z., S.F. and D.W. provided strategic direction. Q.C. and G.R.R. carried out computational modelling and structural analysis and interpreted data. M.P.C., P.Ri., M.S and T.R designed and conducted chemical proteomics experiments. E.Ch. and R.J.C. designed and carried out NMR studies. N.O.F and M.J.W. designed compounds and coordinated chemistry. E.Co. carried out FRET biology experiments. E.Ch., P.R.D and S.C. designed and carried out in-cell concentration experiments. D.H and A.D.F. 
carried out protein X-ray structure determination. N.G. designed, expressed and purified protein constructs. M.R.H. coordinated physicochemical experiments. J.H. conducted protein NMR experiments. A.K. and D.M.M designed and conducted CETSA experiments. E.L designed and conducted subcellular fractionation experiments. N.O. and P.B.R conducted biophysical testing. P.P. conducted imaging analysis. T.C. coordinated biology, interpreted data and coordinated manuscript preparation. All authors discussed results and commented on the manuscript.

\section{Present Addresses}

${ }^{\ominus}$ IFM Therapeutics LLC, 855 Boylston Street, 11th Floor, Boston, MA 02116, USA

${ }^{\Delta}$ Ra Pharmaceuticals, 87 Cambridge Park Drive, Cambridge, MA 02140, USA

${ }^{\Omega}$ Astex Pharmaceuticals, 436 Cambridge Science Park, Milton Road, Cambridge CB4 0QA, UK

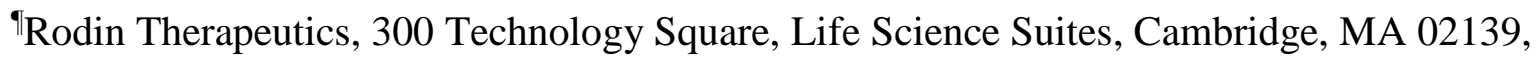
USA

${ }^{\partial}$ Shire, 300 Shire Way, Lexington, MA 02421, USA

${ }^{¥}$ Cedilla Therapeutics, 38 Sidney Street, 2nd Floor, Cambridge, MA 02139, USA

${ }^{\Phi}$ Celgene Corporation, 200 Cambridge Park Drive, Cambridge, MA 02140, USA

${ }^{\perp}$ Northern Institute for Cancer Research, School of Chemistry, Bedson Building, Newcastle University, Newcastle upon Tyne, NE1 7RU, UK

${ }^{\int}$ Repare Therapeutics USA Inc., One Broadway, $14^{\text {th }}$ Floor, Cambridge, MA 02142, USA

\section{Notes}

D.M.M. is a co-founder of Pelago Bioscience. 


\section{ACKNOWLEDGEMENTS}

The authors wish to thank K. Jacques and X. Zhu for assistance with cloning for protein production, J. Huang and A. Rosen for expert technical assistance in generating biological data, S. Boiko for contributing to siRNA immunofluorescence work, G. Guzman and S. A. Carr for assistance with chemoproteomics and A. Markovets for gene expression data. The structural and analytical chemistry group are thanked for expert purification and structural determination of compounds, particularly K. Gibson for acquisition of NMR spectra. I. Roberts and L. Rosenbrier-Ribeiro are thanked for advice on screening data and B. Prince for X-ray crystallography expertise. J. Scott, B. Yang, J. Kettle, J. Zhang and A. Bloecher are thanked for useful discussions on this manuscript.

\section{REFERENCES}

[1] Ranuncolo, S. M., Polo, J. M., Dierov, J., Singer, M., Kuo, T., Greally, J., Green, R., Carroll, M., and Melnick, A. (2007) Bcl-6 mediates the germinal center B cell phenotype and lymphomagenesis through transcriptional repression of the DNA-damage sensor ATR, Nat. Immunol. 8, 705-714.

[2] Basso, K., and Dalla-Favera, R. (2012) Roles of BCL6 in normal and transformed germinal center B cells, Immunol. Rev. 247, 172-183.

[3] Pasqualucci, L., and Dalla-Favera, R. (2014) SnapShot: Diffuse Large B Cell Lymphoma, Cancer Cell 25, 132-132.e131.

[4] Cattoretti, G., Pasqualucci, L., Ballon, G., Tam, W., Nandula, S. V., Shen, Q., Mo, T., Murty, V. V., and Dalla-Favera, R. (2005) Deregulated BCL6 expression recapitulates the pathogenesis of human diffuse large B cell lymphomas in mice, Cancer Cell 7, 445455.

[5] Cardenas, M. G., Yu, W., Beguelin, W., Teater, M. R., Geng, H., Goldstein, R. L., Oswald, E., Hatzi, K., Yang, S. N., Cohen, J., Shaknovich, R., Vanommeslaeghe, K., Cheng, H., Liang, D., Cho, H. J., Abbott, J., Tam, W., Du, W., Leonard, J. P., Elemento, O., Cerchietti, L., Cierpicki, T., Xue, F., MacKerell, A. D., Jr., and Melnick, A. M. (2016) Rationally designed BCL6 inhibitors target activated B cell diffuse large B cell lymphoma, J. Clin. Invest. 126, 3351-3362.

[6] Cerchietti, L. C., Yang, S. N., Shaknovich, R., Hatzi, K., Polo, J. M., Chadburn, A., Dowdy, S. F., and Melnick, A. (2009) A peptomimetic inhibitor of BCL6 with potent antilymphoma effects in vitro and in vivo, Blood 113, 3397-3405.

[7] Cardenas, M. G., Oswald, E., Yu, W., Xue, F., MacKerell, A. D., Jr., and Melnick, A. M. (2017) The Expanding Role of the BCL6 Oncoprotein as a Cancer Therapeutic Target, Clin. Cancer Res. 23, 885-893. 
[8] Kaelin Jr, W. G. (2017) Common pitfalls in preclinical cancer target validation, Nat. Rev. Cancer 17, 425-440.

[9] Huynh, K. D., and Bardwell, V. J. (1998) The BCL-6 POZ domain and other POZ domains interact with the co-repressors N-CoR and SMRT, Oncogene 17, 2473-2484.

[10] Huynh, K. D., Fischle, W., Verdin, E., and Bardwell, V. J. (2000) BCoR, a novel corepressor involved in BCL-6 repression, Genes Dev 14, 1810-1823.

[11] Hatzi, K., Jiang, Y., Huang, C., Garrett-Bakelman, F., Gearhart, M. D., Giannopoulou, E. G., Zumbo, P., Kirouac, K., Bhaskara, S., Polo, J. M., Kormaksson, M., MacKerell, A. D., Jr., Xue, F., Mason, C. E., Hiebert, S. W., Prive, G. G., Cerchietti, L., Bardwell, V. J., Elemento, O., and Melnick, A. (2013) A hybrid mechanism of action for BCL6 in B cells defined by formation of functionally distinct complexes at enhancers and promoters, Cell Rep. 4, 578-588.

[12] Scott, D. E., Bayly, A. R., Abell, C., and Skidmore, J. (2016) Small molecules, big targets: drug discovery faces the protein-protein interaction challenge, Nat. Rev. Drug Discov $15,533-550$.

[13] Sakamoto, K., Sogabe, S., Kamada, Y., Sakai, N., Asano, K., Yoshimatsu, M., Ida, K., Imaeda, Y., and Sakamoto, J.-i. (2017) Discovery of high-affinity BCL6-binding peptide and its structure-activity relationship, Biochem. Biophys. Res. Commun. 482, 310-316.

[14] Kamada, Y., Sakai, N., Sogabe, S., Ida, K., Oki, H., Sakamoto, K., Lane, W., Snell, G., Iida, M., Imaeda, Y., Sakamoto, J., and Matsui, J. (2017) Discovery of a B-Cell Lymphoma 6 Protein-Protein Interaction Inhibitor by a Biophysics-Driven FragmentBased Approach, J. Med. Chem. 60, 4358-4368.

[15] McCoull, W., Abrams, R. D., Anderson, E., Blades, K., Barton, P., Box, M., Burgess, J., Byth, K., Cao, Q., Chuaqui, C., Carbajo, R. J., Cheung, T., Code, E., Ferguson, A. D., Fillery, S., Fuller, N. O., Gangl, E., Gao, N., Grist, M., Hargreaves, D., Howard, M. R., Hu, J., Kemmitt, P. D., Nelson, J. E., O'Connell, N., Prince, D. B., Raubo, P., Rawlins, P. B., Robb, G. R., Shi, J., Waring, M. J., Whittaker, D., Wylot, M., and Zhu, X. (2017) Discovery of Pyrazolo[1,5-a]pyrimidine B-Cell Lymphoma 6 (BCL6) Binders and Optimization to High Affinity Macrocyclic Inhibitors, J. Med. Chem. 60, 4386-4402.

[16] Molina, D. M., Jafari, R., Ignatushchenko, M., Seki, T., Larsson, E. A., Dan, C., Sreekumar, L., Cao, Y., and Nordlund, P. (2013) Monitoring Drug Target Engagement in Cells and Tissues Using the Cellular Thermal Shift Assay, Science 341, 84-87.

[17] Wu, P., Nielsen, T. E., and Clausen, M. H. (2016) Small-molecule kinase inhibitors: an analysis of FDA-approved drugs, Drug Discovery Today 21, 5-10.

[18] Kettle, J. G., and Wilson, D. M. (2016) Standing on the shoulders of giants: a retrospective analysis of kinase drug discovery at AstraZeneca, Drug Discovery Today 21, 15961608.

[19] Contrino, B., Miele, E., Tomlinson, R., Castaldi, M. P., and Ricchiuto, P. (2017) DOSCHEDA: a web application for interactive chemoproteomics data analysis, PeerJ Comput. Sci. 3:e129.

[20] Duan, S., Cermak, L., Pagan, J. K., Rossi, M., Martinengo, C., di Celle, P. F., Chapuy, B., Shipp, M., Chiarle, R., and Pagano, M. (2012) FBXO11 targets BCL6 for degradation and is inactivated in diffuse large B-cell lymphomas, Nature 481, 90-93.

[21] Kerres, N., Steurer, S., Schlager, S., Bader, G., Berger, H., Caligiuri, M., Dank, C., Engen, J. R., Ettmayer, P., Fischerauer, B., Flotzinger, G., Gerlach, D., Gerstberger, T., Gmaschitz, T., Greb, P., Han, B., Heyes, E., Iacob, R. E., Kessler, D., Kolle, H., Lamarre, L., Lancia, D. R., Lucas, S., Mayer, M., Mayr, K., Mischerikow, N., Muck, K., Peinsipp, C., Petermann, O., Reiser, U., Rudolph, D., Rumpel, K., Salomon, C., Scharn, D., Schnitzer, R., Schrenk, A., Schweifer, N., Thompson, D., Traxler, E., 
Varecka, R., Voss, T., Weiss-Puxbaum, A., Winkler, S., Zheng, X., Zoephel, A., Kraut, N., McConnell, D., Pearson, M., and Koegl, M. (2017) Chemically Induced Degradation of the Oncogenic Transcription Factor BCL6, Cell Rep. 20, 2860-2875.

[22] Toure, M., and Crews, C. M. (2016) Small-Molecule PROTACS: New Approaches to Protein Degradation, Angew. Chem., Int. Ed. Engl. 55, 1966-1973.

[23] Tinworth, C. P., Lithgow, H., and Churcher, I. (2016) Small molecule-mediated protein knockdown as a new approach to drug discovery, MedChemComm 7, 2206-2216.

[24] Winter, G. E., Buckley, D. L., Paulk, J., Roberts, J. M., Souza, A., Dhe-Paganon, S., and Bradner, J. E. (2015) Phthalimide conjugation as a strategy for in vivo target protein degradation, Science 348, 1376-1381.

[25] Lu, J., Qian, Y., Altieri, M., Dong, H., Wang, J., Raina, K., Hines, J., Winkler, James D., Crew, Andrew P., Coleman, K., and Crews, Craig M. (2015) Hijacking the E3 Ubiquitin Ligase Cereblon to Efficiently Target BRD4, Cell Chem. Biol. 22, 755763.

[26] Collins, I., Wang, H., Caldwell, J. J., and Chopra, R. (2017) Chemical approaches to targeted protein degradation through modulation of the ubiquitin-proteasome pathway, Biochemical J.l 474, 1127-1147.

[27] Yoon, H.-G., Chan, D. W., Huang, Z.-Q., Li, J., Fondell, J. D., Qin, J., and Wong, J. (2003) Purification and functional characterization of the human N-CoR complex: the roles of HDAC3, TBL1 and TBLR1, EMBO J. 22, 1336-1346.

[28] Parekh, S., Polo, J. M., Shaknovich, R., Juszczynski, P., Lev, P., Ranuncolo, S. M., Yin, Y., Klein, U., Cattoretti, G., Favera, R. D., Shipp, M. A., and Melnick, A. (2007) BCL6 programs lymphoma cells for survival and differentiation through distinct biochemical mechanisms, Blood 110, 2067-2074.

[29] Hideshima, T., Mitsiades, C., Ikeda, H., Chauhan, D., Raje, N., Gorgun, G., Hideshima, H., Munshi, N. C., Richardson, P. G., Carrasco, D. R., and Anderson, K. C. (2010) A proto-oncogene BCL6 is up-regulated in the bone marrow microenvironment in multiple myeloma cells, Blood 115, 3772-3775.

[30] Wappett, M., Dulak, A., Yang, Z. R., Al-Watban, A., Bradford, J. R., and Dry, J. R. (2016) Multi-omic measurement of mutually exclusive loss-of-function enriches for candidate synthetic lethal gene pairs, BMC Genomics 17, 65.

[31] Tunyaplin, C., Shaffer, A. L., Angelin-Duclos, C. D., Yu, X., Staudt, L. M., and Calame, K. L. (2004) Direct Repression of prdm1 by Bcl-6 Inhibits Plasmacytic Differentiation, J. Immunol. 173, 1158-1165.

[32] Polo, J. M., Juszczynski, P., Monti, S., Cerchietti, L., Ye, K., Greally, J. M., Shipp, M., and Melnick, A. (2007) Transcriptional signature with differential expression of BCL6 target genes accurately identifies BCL6-dependent diffuse large B cell lymphomas, Proc. Nat. Acad. Sci. U. S. A. 104, 3207-3212.

[33] Knutson, S. K., Wigle, T. J., Warholic, N. M., Sneeringer, C. J., Allain, C. J., Klaus, C. R., Sacks, J. D., Raimondi, A., Majer, C. R., Song, J., Scott, M. P., Jin, L., Smith, J. J., Olhava, E. J., Chesworth, R., Moyer, M. P., Richon, V. M., Copeland, R. A., Keilhack, H., Pollock, R. M., and Kuntz, K. W. (2012) A selective inhibitor of EZH2 blocks H3K27 methylation and kills mutant lymphoma cells, Nat. Chem. Biol. 8, 890-896.

[34] Albagli, O., Lindon, C., Lantoine, D., Quief, S., Puvion, E., Pinset, C., and PuvionDutilleul, F. (2000) DNA replication progresses on the periphery of nuclear aggregates formed by the BCL6 transcription factor, Mol. Cell. Biol. 20, 8560-8570.

[35] Mateus, A., Matsson, P., and Artursson, P. (2013) Rapid Measurement of Intracellular Unbound Drug Concentrations, Mol. Pharmaceutics 10, 2467-2478.

[36] Mateus, A., Gordon, L. J., Wayne, G. J., Almqvist, H., Axelsson, H., Seashore-Ludlow, B., Treyer, A., Matsson, P., Lundbäck, T., West, A., Hann, M. M., and Artursson, P. 
(2017) Prediction of intracellular exposure bridges the gap between target- and cellbased drug discovery, Proc. Nat. Acad. Sci. U. S. A. 114, E6231-E6239.

[37] Teuscher, K. B., Zhang, M., and Ji, H. (2017) A Versatile Method to Determine the Cellular Bioavailability of Small-Molecule Inhibitors, J. Med. Chem. 60, 157-169.

[38] Zhang, X., Wang, R., Piotrowski, M., Zhang, H., and Leach, K. L. (2015) Intracellular concentrations determine the cytotoxicity of adefovir, cidofovir and tenofovir, Toxicol. In Vitro 29, 251-258.

[39] Murai, J., Huang, S.-y. N., Das, B. B., Renaud, A., Zhang, Y., Doroshow, J. H., Ji, J., Takeda, S., and Pommier, Y. (2012) Trapping of PARP1 and PARP2 by Clinical PARP Inhibitors, Cancer Res. 72, 5588-5599.

[40] Beguelin, W., Popovic, R., Teater, M., Jiang, Y., Bunting, K. L., Rosen, M., Shen, H., Yang, S. N., Wang, L., Ezponda, T., Martinez-Garcia, E., Zhang, H., Zheng, Y., Verma, S. K., McCabe, M. T., Ott, H. M., Van Aller, G. S., Kruger, R. G., Liu, Y., McHugh, C. F., Scott, D. W., Chung, Y. R., Kelleher, N., Shaknovich, R., Creasy, C. L., Gascoyne, R. D., Wong, K. K., Cerchietti, L., Levine, R. L., Abdel-Wahab, O., Licht, J. D., Elemento, O., and Melnick, A. M. (2013) EZH2 is required for germinal center formation and somatic EZH2 mutations promote lymphoid transformation, Cancer Cell $23,677-692$. 